\title{
COVID-19: UNDOING OUR "NORMAL" TO FIND OUR HUMANITY
}

\author{
N. Davids \\ Department of Education Policy Studies \\ Stellenbosch University \\ Stellenbosch, South Africa \\ e-mail: nur@sun.ac.za / https://orcid.org/0000-0002-7588-5814
}

\section{ABSTRACT}

At the time of writing this article South Africa has entered yet another hard lockdown, casting darkening shadows over, if not a hopeful return to "normal", then at least to the establishment of a "new normal". Clearly, even amid the unpredictability and trauma of a virus which strikes in an undifferentiated way across race, class, age, and geopolitical contexts, there should be nagging suspicions about a forward-looking narrative which relies on a repeated reference to "a normal". In the case of the educational institutions, a "new normal" is embodied in virtual spaces of teaching and learning. Seemingly, objectives of embarking on a "new normal" have scant regard for the myriad existing inequities, which continue to render South African educational institutions into categories of either historical advantage, or historical disadvantage. Seemingly too, a "new normal" chooses to disregard the reality that if educational institutions are not on an equal footing, then why is there an uncritical presumption that learners and students, or teachers, for that matter, are able to access and participate in virtual learning in parity? It is a big enough challenge for most learners and students to actively participate in educational settings, when one considers the dismal living conditions of the majority of South Africans. For many of these learners and students, educational settings, even in their poor infrastructural states, represent an escape and haven from the hardships of a life entrenched in poverty. What happens when the expectation of learning shifts entirely to the capacity of the home to become a space of learning? Can we, therefore, continue to speak of a "new normal" when it is evident that there is no "normal", not in our educational institutions, and not in our citizenship?

Keywords: Covid-19, "new normal", democratic citizenship education, crisis, hospitality, teaching, humanity

\section{INTRODUCTION}

Despite the implicit offering of a contractual relationship to all its citizens, it is apparent, within any liberal democracy, that this offering is not on an equal footing to all individuals. Not all individuals or communities are able to engage with the parameters and provisions of the state as equals. Such are the individualistic imperatives of democratic contexts and engagements, 
that experiences of inequality are an inevitable consequence of human endeavours and desires. Depending on whom one engages with, the lived experiences of what it means to be a citizen in South Africa, or what it means to be included, exist on an extreme continuum of full enjoyment, to not having any sense of it at all. Unless democracy is made evident and alive to its citizens in what they experience in their daily lives, it is impossible to expect citizens to know what it means to be and act democratically, let alone aspire towards it. Certainly, when it comes to South Africa, conceptions and practices of citizenship are neither "normal", nor equal; mirroring instead the wide contextual and communal disparities, most of which were laid and cemented historically. The kinds of fractured citizenship experienced by a range of individuals and groups - in terms of race, ethnicity, class, culture, religion, gender, sexuality and ablebodiedness - suggest that the assumption of a homogenous conception of citizenship, which applies to all people equally, is both unfounded and unreasonable.

When we shift this conversation to that of education, similar patterns of incongruency are abundantly evident. Our schools, while beset with four iterations of curriculum reform, remain mired in inefficient and ineffective infrastructure. There is seemingly little political will to act on the myriad policy redress, which has accompanied the transition to a democracy. Rapid policy-making as an indicator of transformation has not flowed into policy implementation laying bare not only a fragile democracy, but a vulnerable citizenship, prone to volatile civil unrests and student protests, flamed by increasing bursts of violence and mayhem. Adding fuel to this simmering ember is a global pandemic - the rightfully dreaded, Coronavirus disease, COVID-19. In addition to causing an inconceivable loss of life even in the world's most economically and medically advanced societies, in South Africa COVID-19 has exposed the sheer neglect of a democratic polity in ensuring the very basic infrastructural educational needs of a society, whose majority populace has only ever been privy to oppression and marginalisation.

As the pandemic curtailed and re-defined modes of social interaction, including educational spaces and encounters, it became abundantly evident, for example, that any efforts towards maintaining safety protocols at schools could not be implemented in the absence of taken-for granted amenities, such as running water, sanitation, and classrooms, which were overcrowded by 50-60 learners. Not for the first time, 29 November 2020 marked the deadline for provincial education departments to provide enough classrooms, electricity, water, toilets, perimeter fencing, telephones and internet for all schools. There is nothing extraordinary about this provision, or the deadline. The urgency emanating from a pandemic merely highlighted the state's disregard for its own policies. In this regard, what was required (yet again) was for the national Department of Basic Education to implement the much bandied around National 
Norms and Standards for school infrastructure (DBE 2013). Tragically, like the deadline set in 2016 to eradicate unsafe structures, such as mud schools and asbestos, metal or wood buildings, the one set for 2020 (at the time of writing) had still not been met.

The deeply entrenched disparities between historically advantaged and historically disadvantaged schools are outweighed only by the lack of transformation supposedly implied by desegregated schools. The relatively small percentage of learners, who manage to acquire the economic mobility necessary to meet the exorbitant financial demands of increasingly elitist public schools, are presented with serious hurdles in terms of inclusion, belonging and recognition. Presumptions that all teachers are indeed equipped or willing to teach on the topic of democratic citizenship education, or that all schools are indeed capable of modelling and nurturing the environments necessary for democratic forms of engagement and being, are worryingly misplaced (Davids 2019).

Expectations placed on schools in advancing the imperatives of a socially just democracy are as vividly captured in higher education policy reform. According to Education White Paper 3 (DoE 1997, 1.7) "The transformation of higher education is part of the broader process of South Africa's political, social and economic transition, which includes political democratisation, economic reconstruction and development, and redistributive social policies aimed at equity". Similar to the fault-lines revealed in the country's basic education system, the pandemic has demonstrated, asserts Badat (2020), that higher education continues to be a powerful mechanism of unequal forms of social reproduction and exclusion of students from working class and rural impoverished backgrounds. One of the greatest concerns with the ongoing metanarrative of transformation is its slippages into a fixation with racial representation. As a result, we have seen a significant surge in the number of student enrolments from historically marginalised communities. This massification is perceived as critical to the democratisation and diversification of higher education, and hence to society. Yet, as is evident by the persistent drum of student protests, external access has done little to address the increasing concerns about academic alienation, institutional non-belonging, and redressing social and economic inequalities.

It is apparent even from this brief critique of the "normal" condition of education in South Africa, that any conception of standard or convention, as might be implied by "normal", is in disrepute. The current "new normal" in higher education, which relies extensively on online engagement, could further entrench and create new barriers to transformation in and through higher education (Badat 2020). The fact that we continue to refer to historically advantaged and historically disadvantaged educational institutions 26 years into a democracy confirms the existence of an unequal society, which can only perpetuate more extensive disproportions and 
inequities. I would argue, therefore, that we should not return to "normal"; the "normal" to which South Africans have become accustomed, is one based on exceptions. To return to this kind of "normal" means an entrenchment of the state's disregard for dignified forms of citizenship; it also means a normalisation of not being treated as fully human. What such a position yields, is a push into renewed considerations of what might be possible. Specifically, apparent from such an argument are opportunities for what might be gained from the crisis of Covid-19, what these gains might hold for how we conceive of ourselves as citizens, and the implications thereof for democratic citizenship education.

\section{WE ARE NOT WHERE WE THINK WE ARE}

As expected, and demanded, transitioning to a democracy could not and will not be achieved without substantive practical reform, geared simultaneously at undoing the myriad political social inequalities and inequities, while ensuring large-scale social justice reform. This twin endeavour, however, for different complexities, has not always been in sync, and at times, has operated in tension to each other. One of these, as identified by Badat $(2010,7)$, is that an "exclusive concentration on social equity and redress without adequate public funding and academic development initiatives to support under-prepared students has negative implications for quality, compromises the production of high quality graduates with the requisite knowledge competencies and skills, and adversely affects economic development". In turn, notions and practices of transformation are seemingly narrowly interpreted in discourses of racial representation, seen as key as democratising higher education spaces. In the absence of an accompanying measures, focused on participation, inclusion, equal recognition, and belonging, transformation cannot unfold in a meaningful or lasting way. It is this particular concern - a loss of being seen as human beings - which in my opinion, constitutes the core of students' repeated calls for decolonised university spaces. That these calls have intensified especially since 2015 with the \#feesmustfall and \#rhodesmustfall campaigns, confirm that whatever transformation is believed to have occurred within higher education, is clearly not only insufficient, but deficient. Stated differently, and perhaps as a more hopeful assertion, although education is not yet transformed, it does have the potential to transform. But, in order to do so, due caution has to be exercised in relation to what we might understand as a post-pandemic "new normal".

With this in mind - we are indeed in a state and politics of becoming - that is, in the words of Renaissance scholar, Giorgio Agamben (1999, 177), "to both be and not be". We are at once in a condition of a pandemic, in the same way that we are not; we can at once project ourselves beyond this state, in the same way that we might not. The restrictions arising from the pandemic 
have impeded not only our mobility, and how we access and participate in the agora (public square); it has also reframed how we engage with others, imposing a distance of self-restraint and un-intimacy. Covid-19, states Badat (2020, 25):

"[H]as affected all aspects of society, including capital accumulation, production and labour processes, work and employment, state functions, revenue and finances, social services, and modes of interaction and communication - Its impact has followed the contours of class, 'race', gender, age, health and geography, exacerbated the precarity of livelihoods and work, intensified poverty and inequality, reinforced inequities in access to social services and information and communication technologies, and has graphically illuminated the fissures and consequences of neo-liberal capitalism."

We struggle against not being able to act as if things were "normal"; we struggle against the unthinkable of what might or might not be should this "new normal" become our only "normal".

Our new world is one, characterised by unfamiliar and hesitant forms of engagement, massively impeding, creating unprecedented nodes of withdrawal and insularity - a world in which Agamben's (1999) "I can" does not mean anything - "yet it marks what is, for each of us, perhaps the hardest and bitterest experience possible: the experience of potentiality". That is, we can no longer be with others in ways that we have taken for granted, but in not being able to do that which has always informed our way of life, we have the potential to consider other ways of being.

In addition to re-conceptualising and re-navigating our citizenship in the public square, comes an unnerving reminder of our remarkable vulnerability and fragility. And with that (albeit not in all cases), we have entered into "a community without presuppositions" (Agamben 1993, 85), thereby opening the way for us to reconceive how we (re)navigate our life-world with others. To Agamben (1993), there are certain presuppositions on the relationship between life and language - that is, the way humans and animals find expression in lógos (bios). The Greeks, says Agamben $(1995,4)$, used two terms to describe "life": "zoē, which expressed the simple fact of living common to all living beings (animals, men, or gods), and bios, which indicated the form or way of living proper to an individual or a group". When the state, as the biopolitical machine of sovereign power, imposes a relation of exception (as is the case with the lockdown due to a pandemic), which separates zoé from bios, then what emerges, explains Agamben (2000, 3), is bare life, "a form-of-life is a life that can never be separated from its forms". Life or each form of human living, maintains Agamben $(2000,4)$ is neither "prescribed by a specific biological vocation, nor is it assigned by whatever necessity". Instead, he maintains, each form of human living "always retains the character of a possibility; that is, it always puts at stake living itself'. 
Much of the ensuing protests and frustrations against the series of lockdown measures imposed in South Africa and elsewhere, stem from forms of human living which are intent on enjoying unconditional freedom and "irremediably and painfully assigned to happiness" (Agamben 2000, 4). Almost instinctively, therefore, humans seek out new articulations of what it means to live. As a result, despite our unshared identities and differences, we have entered into new communities of co-belonging, connected paradoxically on the one hand, by our masks, and on the other, through social distancing. Our attachment to each other is manifest through our willingness to detach ourselves from those around us, as well as our everyday lives. In this way, we have established new communities of co-belonging, motivated by our collective potentiality to act against a global pandemic.

In addition to suspending what is often the unconsciousness of our being and acting, we have had to change the way we teach in ways that are largely driven by politically derived notions of learning outcomes, rather by educational imperatives. With scant regard for often counter-productive contexts to teaching and learning, we are left with haphazard decisions to transition to digital forms of engagement. I fear that the politicisation of teaching, and presumably learning, might in the end have dire consequences for citizenship education. Much has been made of the necessity of digital technologies (teaching and learning). Technology has become indispensable for learning skills, building knowledge, working, playing, and socially connecting. Of deep concern are the neglected and gaping realities of the contexts, which I have already described. We seemingly speak of this technological shift and indispensability as if all our educational spaces occupy a single and common realm. We have these conversations in a decontextualised unconsciousness, even when we know that to most South Africans, digital or remote learning is as much as an oxymoron as the idea of "physical" or "social distancing" in overcrowded homes and communities.

The truth is that despite its unprecedented advances and capabilities, there are indeed profound limits to digital technologies. Here I am not only referring to the blatantly evident schisms between historically advantaged and historically disadvantaged educational spaces, and hence the accompanying irreconcilable lived experiences of learners or students. I am also not only referring to the mounting concerns that these technologies, and the screens on which they display, may be changing our brain circuitry, eroding our deep reading abilities, memory, and comprehension, with implications for our physical and mental health, education, and relationships. What I am concerned about are the effects of our accelerated reliance on digital technologies on the kinds of citizens we are cultivating - our polity. Our rapid transition (some would say, descent) into the embrace of the Fourth Industrial Revolution, signals that we are in need of thinking that is dependent on the algorithmic computations of technology, that we can 
no longer only rely on traditional forms of human imagination. But, the altered way of life brought about by digital technologies should awaken us to its implicit limits and risks to what it means to being human.

Specifically, it is not that machines have come to replace humans in the strictest sense, but that humans have become embodied in machines. We, therefore, have to stop and give due thought to what happens to the educational encounter between lecturer and student across the detached spaces of screens. We have to ask about human connections in an era of intensified human connectivity. How do we open ourselves to these new forms of engagement, while remaining reflectively loyal to our mutuality as human beings?

The absence of physical and verbal cues implies not only an absence of human engagement; it removes the need to engage with others, to be around others, their ideas and their differences. It is no coincidence that as certain world leaders have swayed and floundered in their mismanaged responses to the pandemic, we have seen a surge in stigma, polarization, racism and hate speech against vulnerable communities (Khazanchi, Evans and, Marcelin 2020). Here, I am not only referring to leadership forms, embroiled in arrogance and bravado, I am also referring to leadership, which falter in terms of ensuring humane and corruption-free responses - both of these failings continue to stir civil unrest, immense hardship in daily living, mistrust and a loss of regard for the other. Many developing countries face additional challenges with increased threats to democracy and human rights - their ways of action and engagement are limited, and authoritarian regimes use the opportunity for further cuts in civic rights, freedom of speech, participation of citizens etc. Vulnerable and marginalized communities, especially in high density, socio-economically unequal and predominantly migrant areas, are additionally affected by the new measures; the social distance and stigmatization can increase, as well as harassment based on political, racial or religious biases (Cilliers et al. 2020).

While I recognise the criticality of education as a foundational premise of any functioning society, I have serious questions about our understandings and purpose of education. It is hard to ignore the reality that for too many students as well as academics and teachers, the attainment of education is viewed as a means to a qualification end. The urgency of online teaching and learning suggest a singular focus on not only producing student outputs, but on producing students, who are merely technicians of learning. Who are these students, these young people, we are seemingly intent upon producing? With their degrees in their hands, what kinds of human beings are they?

Quite explicitly, an online learning community is rid of the complexities implicit within any diverse group of people, thereby raising inevitable questions about the kind of people (not only students) universities stand to produce. It would seem that while online learning 
communities provide spaces for "safer" engagement (in terms of social distancing), they present "unsafe" and unreliable options in terms of cultivating the spaces, necessary for a citizenship, based on hospitality, inclusion, recognition, tolerance, empathy and compassion - significantly, the very types of values required to undo the "normal", which has thus far defined citizenship and education in post-apartheid South Africa.

\section{A CRISIS IS ONLY A CRISIS WHEN IT LEAVES US IN OUR “NORMAL”}

There is always a temptation, contends Arendt $(1968,170)$, "to believe that we are dealing with specific problems confined within historical and national boundaries and of importance only to those immediately affected". Dominant, global responses to the pandemic have been no different Yet, it is precisely this belief, "that in our time has consistently proved false" (Arendt 1968, 170). Crisis "tears away facades and obliterates prejudices"; it forces us back to the questions themselves and requires from us either new or old answers, but in any case, direct judgements. The world is always being worn out by its inhabitants, and its inhabitants are constantly changing - hence, our perpetual state of becoming. Understood in this way, a crisis forces us to take stock of the taken-for-grantedness of our daily lives and views, of how we see the world and others, of our beliefs, our politics, our biases, and the extent to which we allow perception and myth to interfere, or disrupt us from "seeing" others as they are, and not how we choose to see them. The crisis forces us to hit a pause button, to recognise the damage that we do to others, ourselves, and the world around us.

Think about what happened when we were all under lockdown - think about our natural world, the air we breathe, restored and regenerated - it was as if we needed to temporarily step oud of this world in order to save it from ourselves. To preserve the world against the harm and mortality of its creators and inhabitants, it must be constantly set right, recharged, set anew. It is the responsibility of education to preserve this newness and introduce it as a new thing into an old world (Arendt 1968). Arendt (1968) makes a compelling argument: what makes a crisis a crisis, is the absence of crisis. In other words, we need a crisis to be reminded of our humanity and mortality. What does this mean for us as educational researchers, social scientists, academics, teachers, or students?

Firstly, the responsibility of responding to a crisis is our collective responsibility - there are no alternatives, but to respond. As people, who are interested in, or concerned about citizenship, it is our responsibility to keep working on identifying pedagogical problems, developing better explanations and encouraging reflections that expand our possibilities for action. At a time like this, our roles are not minimised, they are intensified - the digital space demands that we find new ways of cultivating communities of co-belonging. That we are living 
in "a community without presuppositions", and in "bare life" (Agamben 2000), should, following Agamben (2000), draw us towards a recognition of the sacredness of life. This implies a dyadic consciousness of who we are, and who we are in relation to others. Within (higher) education, this speaks to a renewed attentiveness to why we teach, what we teach, and how we teach. Most importantly, given the bareness of our forms of living, it necessitates a critical consideration of who we teach, and the kinds of human beings we hope to see emerge from our teaching. As such, the spotlight reflects on the teacher and the teaching - exposing questions about practices of hospitality, inclusion, tolerance and regard for the other. In this regard, the first point of departure is to recognise that although digital teaching and learning have become constitutive of our "new normal", we cannot accept it as an uncritical normalisation (when we know that all teachers and learners do not access this virtual space on an equal footing). Regardless of whether every single student or learner in South Africa is issued with a laptop, the contexts of the majority of South Africans are not conducive to online learning. That this has become the prevailing pathway for teaching and learning, should prod us to become especially alert to the associated pitfalls - not only in terms of socio-economic and domestic hindrances and deficiencies, but the emotional demands implicit in any educational approach, which sets out to teach via a screen. As humans, we are social beings. As social beings, we are story-telling beings. We crave human connection, conversation, affirmation and recognition. To assume that we can simply do without these affective needs, is to have an impoverished sense of what it means to be human.

Secondly, a global pandemic implies much more than a disruption that needs to be addressed with digital learning models. Rather, in following Arendt's (1968, 180) advice, teachers are "always educating for a world that is or is becoming out of joint, for this is the basic human situation ...", perhaps now is the time to pay renewed attention to the principles of global citizenship education - given that the effects of the pandemic have been global with its most dire consequences on citizenship. There is no better time than now for us as teachers and academics to use our pedagogies to encourage and guide those we teach to recognise the mutual obligations that individuals have to one another. A good starting point is to acknowledge as Damian Barr (2020) does in his poem: "We are in the same storm, but not in the same boat ..."

"Your ship can be shipwrecked and mine might not be.

Or vice versa.

For some, quarantine is optimal: a moment of reflection, or reconnection.

Easy, in flip flops, with a whiskey or tea.

For others, this is a desperate crisis.

For others, it is facing loneliness. 
For some, peace, rest time, vacation.

Yet for others, Torture: How am I going to pay my bills?"

As we think about how to navigate our new "normal", we should also critically reflect upon the silences of our "old normal" - uneven global development, power structures, and socioeconomic disparities that lead to increased gaps, widen inequalities and injustice, with every new crisis. Our concern about education is undoubtedly a legitimate one, but if we fail to change the way in which we conceive of the purpose of education, then this pandemic will indeed only be a crisis - from which we would have learnt nothing. Curriculum reform in both basic and higher education is embedded in the criticality of democratic citizenship education. At a policy level there is a strong emphasis and recognition that it is only through education that we are able to realise the desired conceptions and practices of citizenship, necessary for the flourishing of this democracy. The unfortunate reality, however, is that citizenship education is only sought or prioritised when we are faced with a controversy or protest.

\section{HOSPITALITY AS OUR NEW HUMANITY}

As we prepare to commence our 2021 academic year through online communities, we have to re-frame our teacher-student/teaching-learning encounter in languages of mutual regard, hospitality, tolerance, empathy, compassion, respecting diversity and equipping those we teach with the values of what it means to act with humanity. And if we are to achieve these valuebased outcomes, then it is not enough to only teach about it, we have to be prepared to embody it. In other words, we have to be prepared to be the values about which we talk. Learners and students alike take their cues not only from what we teach, but how we teach (Waghid and Davids 2020) - this does not change because we are no longer in the physical presence of teaching and learning. Indeed, we need to even more cognisant of how we might incorporate and include deliberations and reflections on our mutuality as we teach.

When I am asked why I teach, or what I conceive the purpose of education to be, I normally respond that it is to foster human beings, who are able to think. My primary goal when I teach is to get students to think about what they are reading, what I am saying, what they are saying, why they are saying it, and consider the possibility, that just perhaps, there might be another view. As expressed by David Foster Wallace (2005),

"teaching you how to think is actually shorthand for a much deeper, more serious idea: learning how to think really means learning how to exercise some control over how and what you think. It means being conscious and aware enough to choose what you pay attention to and to choose how you construct meaning from experience". 
Immediately, however, I want to add that thinking rationally is not the only kind of intelligence, and certainly rationality is not the only feature of citizenship education. In the words of 13 thcentury Persian poet, and Sufi mystic, Jalāl ad-Dīn Muhammad Rūmī Rumi, "There is another kind of tablet, one Already completed and preserved inside you" -

"There are two kinds of intelligence: one acquired,

As a child in school memorizes facts and concepts

With such intelligence you rise in the world.

There is another kind of tablet, one

Already completed and preserved inside you.

This other intelligence does not turn yellow or stagnate.

It's fluid, and it doesn't move from outside to inside

Through the conduits of plumbing learning.

This second knowing is a fountainhead

From within you, moving out."

What Rumi has in mind is that there are other intuitions, experiences (perceived and real) particular emotions - at play, which yield to how democratic citizenship education is both conceptualised and embodied. How we extend hospitality, tolerance, empathy and compassion, for example, how we choose to "see" and engage with others, live in us. We are socialised into emotions and emotional expressions well before we are able to make sense of it. When we think of hospitality in the everyday sense of the word, we are inclined to think of it in terms of things that are offered and received (typically food, shelter etc) - often as a relation between a host and a guest, whether in families or cities or countries. Algerian-French philosopher, Jacques Derrida refers to this as a conditional hospitality - "We offer hospitality only on the condition that the other follow our rules, our way of life, even our language, our culture, our political system, and so on" (Derrida in Borradori 2003, 162).

Yet, hospitality in the educational encounter cannot be conditional. There is no sameness; there is only diversity and difference. Hospitality as an educational encounter, therefore, is an embrace of acceptance, so that all students (people) find belonging. In extending hospitality, we recognise our shared humanity - thereby drawing upon added emotions of empathy, care and compassion. But hospitality only becomes apparent if we are prepared to set aside our preconceived ideas of others. Here, we need to think about how we respond or assess our students. Do we recognise some, while misrecognising others? Do we lift some, while running others down? So much about extending hospitality to others depends on how we conceive ourselves in relation to others. If we are harmed or damaged in our thinking, then we are at risk 
of extending harmful ideas and views. As an example, apartheid has not only caused harm to those, who were oppressed; it has also caused harm to those who perpetrated the oppression, because they have a distorted sense of what it means to be and act with humanity.

Hospitality therefore resides in our capacity to include all others - regardless of their differences. It finds expression in patience, open-mindedness, and tolerance. In the Socratic sense, tolerance is about the pursuit of truth - that is, a preparedness to see the truth in others. This implies acknowledging the autonomy of others, by not restricting their right to be. In many ways, tolerance embodies a pragmatic response to the basic need to coexist with others. To Amy Gutmann (1987, 304), tolerance is an act of "agreeing to disagree about beliefs and practices that are a matter of basic liberty" - as a way to ensure larger participation of people as civic equals in such encounters. For her, once one has agreed to disagree in educational encounters, the possibility is always there to recognize publicly one another's political, cultural and religious differences (Gutmann 1987, 305). In this way, tolerance and recognition of differences are inseparable acts of human behaviour. When we show tolerance, we stop ourselves from imposing any single substantive systems of beliefs and practices on others.

With a willingness to engage with difference and from another's perspective comes a broadening of our own lived experiences and vantage points, and hence our capacity to act with compassion and empathy. I mention this to highlight the interconnectedness of what it means to act with humanity. One cannot have tolerance, without recognising the importance of hospitality; similarly, one cannot show hospitality, without having compassion or empathy for another.

Ultimately, hospitality succeeds when others (students, citizens, immigrants) feel a sense of belonging. Belonging can take a number of forms - from that which is physically manifested and concrete, to abstract ways - and varies from person to person. At times, an individual might have a strong sense of belonging, particularly when his or her particular values or perspectives are confirmed; other times, feeling a sense of belonging might be under major strain - leading to an individual feeling disconnected, unseen, and mis-recognised. Feeling a sense of belonging is critical to the wellbeing and recognition of individuals, groups, or communities. In educational settings, notions and experiences of belonging adopt added complexities and nuances - which might not be immediately evident to teachers or learners or students. Experiencing a sense of belonging is intricately embedded in what it means to be included that is, to be drawn into the presence, and the presence of others. When students experience non-belonging or exclusion, they become alienated not only from the contexts in which they find themselves, but from what it means to be seen and treated as human beings.

Finally, human flourishing is possible only if we begin to act in ways, which not only 
recognise our mutuality, but if we are prepared to put in place the measures to sustain that mutuality. Citizenship education provides us with a language to negotiate renewed understandings and practices of civic engagement and disagreement; it is up to us to accept this responsibility. Our entire existence as a human collective relies on new perspectives. The covid19 pandemic as a crisis, is one instance of a new perspective. Our views and arguments are always in becoming; we can never exhaust understandings of ourselves or the world in which we find ourselves. It becomes imperative, therefore, to recognise that notions of a "new normal" have to depart from addressing that which has never been "normal" in the first place. At the heart of what has not been "normal" is to see and live in humane engagement with others. Our incapacity to engage as human beings, and with the humanity of others, have rendered us into isolated pockets of self-preoccupation. Any idea of a "new normal", therefore, has to both depart and return to how we find improved ways of reconnecting with our humanity.

\section{REFERENCES}

Agamben, G. 1993. The coming community: Theory out of bounds (Vol. 1). Translated by M. Hardt. Minneapolis, MN: University of Minnesota Press.

Agamben, G. 1995 Homo Sacer: Sovereign power and bare life. Translated by D. Heller-Roazen. Stanford, CA.: Stanford University Press.

Agamben, G. 2000. Means without ends: Notes on politics. Translated by V. Binetti and C. Casarino. Minneapolis: University of Minnesota Press.

Agamben, G. 1999. Potentialities: Collected essays in Philosophy. Translated by D. Heller-Roazen. Stanford, CA.: Stanford University Press.

Arendt, H. 1968. Between Past and Future. Harmondsworth: Penguin.

Badat, S. 2010. "The challenges of transformation in higher education and training institutions in South Africa", paper commissioned by the Development Bank of Southern Africa, viewed 13 June 2016. https://www.ru.ac.za/.../The\%20 Challenges\%20of\%20Transformation\%20in\%20High.

Badat, S. 2020. "Reproduction, transformation and public South African higher education during and beyond Covid-19." Transformation: Critical perspectives on Southern Africa 104: 24-42.

Barr, D. 2020. We are not in the same boat. https:/www.dspretoria.co.za/wp-content/uploads/ 2020/05/We-are-not-all-in-the-sameboat.pdf.

Borradori, G. 2003. Philosophy in a time of terror: Dialogues with Jürgen Habermas and Jacques Derrida. Chicago, IL: The University of Chicago Press.

Cilliers, J., M. Oosthuizen, S. Kwasi, K. Alexander, T. K. Pooe, Y. Kouassi, and J. D. Moyer. 2020. The poor lose again: The impact of COVID-19 on Africa. Institute for Security Studies. https://issafrica.org/iss-today/the-poor-lose-again-impact-of-covid-19-on-africa.

Davids, N. 2019. "Schools as restorative spaces for democratic citizenship education." Journal of Education 77: 79-93.

DBE see Department of Basic Education.

Department of Basic Education. 2013. National Norms and Standards for school Infrastructure. Pretoria: Government Printers.

Department of Education. 1997. Education White Paper 3: A programme for the transformation of higher education. Pretoria: Government Printers. 
DoE see Department of Education.

Gutmann, A. 1987. Democratic Education. Princeton, NJ: Princeton University Press.

Khazanchi, R., C. T. Evans, and J. R. Marcelin. 2020. "Racism, not race, drives inequity across the COVID-19 continuum." JAMA Netw Open 3(9): e2019933. https://jamanetwork.com/journals/ jamanetworkopen/fullarticle/2770954.

Waghid, Y., and N. Davids. 2020. Teachers Matter: Educational Philosophy and Authentic Learning. Lanham, MD (US): Rowman \& Littlefield - Lexington Series

Wallace, D. F. 2005. This is water. https://fs.blog/2012/04/david-foster-wallace-this-is-water/. 